\title{
Analysis of results of expert professiographical survey of activity of managers of the international trade organization
}

\author{
V. M. Korolchuk, I. S. Ptukha \\ Kyiv National University of Trade and Economics, Kyiv, Ukraine \\ Corresponding author: inna.ptukha@gmail.com
}

Paper received 03.09.18; Accepted for publication 18.09.18.

https://doi.org/10.31174/SEND-PP2018-175VI73-11

\begin{abstract}
The article finds that the indicators of the "Professiographical questionnaire of O. Lipmann" correlate with the results of obtained factor and correlation analyzes. Six factors have been identified: organizational F1 (according to the questionnaire by O. Lipmann - it is language and ethnopsychological properties); professional F2 - is a competitive and emotional characteristics; F3 motivational; F4 - communicative; F5 - functional-dynamic, which is conditioned by estimations of the typological and emotionalvolitional sphere of the surveyed; F6 - intelligent.
\end{abstract}

Keywords: expert professiographical survey, psychogram of a profession, managers, personnel selection, international trade organization.

Introduction. In the context of the globalization of the world economy and the integration of Ukraine into the established system of economic ties, innovation processes in the field of improving and developing the communicative and economic interaction of international trading companies are becoming increasingly important. This is reflected in the intensive growth of international treaties, whose share in the world is estimated at around $34 \%$ of the total volume of foreign direct investment.

It is common knowledge that the causes associated with resources (natural, labor, etc.) have a significant effect on the beginning of activity in one or another country, especially if these resources are available and cheap. At the same time, the quality of human capital is also one of the most important factors in the placement of its trading enterprises and branches in other countries.

The processes of transnational trade and economic cooperation are gradually gaining momentum in Ukraine, which was an incentive for Ukraine to join the World Trade Organization (WTO) and the Association Agreement with the European Union. Currently, the number of companies, including Ukrainian, who are seeking to enter the international market is constantly increasing. In any country or region there are ethnopsychological and socio-cultural features that need to be taken into account in trade and economic interaction. For companies entering the international market it is extremely important to develop the right strategy for selecting managers, taking into account the needs and traditions of the society in which the company conducts its business activities.

It is possible to distinguish a number of reasons that determine the importance of research on the selection of managers for international companies. The first one is that, at the international level, one of the main conditions that determines the success or failure of international business, are the professionals who will work and are the factors of success or risk in the enterprise. Professionals of international companies are raising their professional requirements, increasing the degree and depth of their responsibility and relevance to the availability of professionally important qualities.

Another reason is the rapid growth of activity and competition at the international level, again due to both economic and human factors. The third is that there are not enough managers with successful experience in international trade, due to shortcomings in the formation of human resources. The fourth is to take into account psychological, socio-cultural and ethnopsychological peculiarities of interaction with partners.

After all, the art of being a manager is manifested not only in coordination, communication with representatives of other firms, but also in the ability to take responsibility for themselves, be able to reasonably persuade and achieve the goal.

It is known that $80 \%$ of the problems that arise in the manager's activity are connected with the human factor, which results in a high level of requirements for professional and personal qualities of a specialist (M. Korolchuk, A. Krylov, G. Nikiforov) $[4,9.10]$.

In general, the management of human resources in international companies is considered by most academics as a complicated and complex phenomenon with multi-vector functions, increased risks of employees of these companies.

The analysis of existing official and scientific publications shows serious scientific and methodological gaps in the issues of personnel selection in international companies, inconsistency with the requirements of the employer to the level of qualification of foreign and domestic personnel.

Therefore, it became necessary to study the patterns and problems associated with the selection of personnel in international companies, especially when expanding their foreign economic activity.

The need for a psychological study of the peculiarities of the professional activity of the managers of international trade organizations (MTOs) is related to socio-economic reforms in Ukraine, with the appearance of business representatives into international markets, the entry of Ukraine into the WTO and the integration processes of cooperation with the countries and the European Union, which necessitated the operation of a large number of managers in international trading companies.

Trade and economic relations in the present post-industrial society are formed in the conditions of globalization, financial risks and intensification of competition. At the same time, in the process of expanding interaction with enterprises and organizations of other countries, in the condi- 
tions of market relations, along with cooperation, the struggle of interests for sales markets take place. Alongside, we observe the aggravation of relations and manifestations of rivalry, ethnopsychological peculiarities and features of mentality, which requires from managers of international companies general managerial abilities together with more specific, professionally important qualities. In order to ensure the efficiency of professional activities in the international trading market, there is a need for a expert professional study of professionally important qualities as determinants of the success of the managers of the international organization.

A brief overview of publications on the topic. It is known that the psychological study and analysis of professional activity, prediction and determination of professionally important qualities involves obtaining empirical measurements, their systematization, matching requirements of conditions and peculiarities of activity with the presence of important psychological characteristics and properties of a specialist (V. Bodrov, N. Pryazhinikov and E. Pryazhinikova, L. Karamushka, E. Klimov, M. Korolchuk, V. Korolchuk, M. Makarenko).

Consequently, most scholars believe that an integrated approach to studying and analyzing the content and structural characteristics of the profession in order to establish the peculiarities of the relationship of the subject with the components of the activity and its functional support is called professional psychogram.

According to the professiographical results, a professional psychogram is compiled, which includes a collection of data on the specifics of technical, technological, psychological, psycho-physiological characteristics of the process of activity and its conditions and organization.

According to professiographical and psychological analysis, the psychogram of a particular profession is defined - psychological components, which is the result of an interpretive analysis of the operational and technological content of a particular work activity (in our case, the managers of the MTO). As a result, this enables to characterize the complex of professionally important qualities that are realized in a particular activity and determine its effective implementation (V. Bodrov, L. Karamushka, E. Klimov, M. Korolchuk, A. Mazaraki and S. Maksimenko).

According to V. Bodrov, M. Korolchuk and V. Kraynyuk, M. Makarenko, N. Pryazhinikov, the professional psychogram reproduces the systemic organization and regulation of concrete labor activity and is carried out according to the following principles: specificity (description of the concrete profession, specialty); stage (sequence of information gathering); the study of activity (analytical and empirical) and the resulting stages $[1,4,5,8]$.

Based on goals and objectives of O. Ivanova research, she distinguishes the following professiographical types as: informational, indicative-diagnostic, constructive, methodological, and diagnostic [8, p. 31-34].

According to the results of the analysis of the content and structure of the professional psychogram A. Markov [8, p. 23] systematizes them. Thus, the author points out the following features of the scientific approaches to professional psychogram as: a complex professional psychogram (according to K. Platonov and Y. Kotelyova), a psychologically oriented professional psyhogram (according to E. Garber) and a personality-modular approach (in the interpretation of A. Markova [8, p. 23-24]). The listed methodological approaches, principles and types of professional psychogram have appeared to be the basis of certain schemes of psychological study of a person in professional activity.

Consequently, the specifics of the professional psychogram (profiling) in order to solve the problems of psychological, psycho-physiological orientation is to determine the most important professional qualities which are determinants, which ensure the effective implementation of the individual in a particular type of activity and the level of success of the training.

Thus, based on the analysis of the most important elements of the studied profession, there are psychic qualities with corresponding variables (which are compensated or not by other qualities), as well as qualities that are psychological contraindications for studying and working on a particular specialty. That is, the professionally important qualities have decisive determinants, as well as necessary and desirable and incompatible with certain activities.

In the final part of the professional psychogram it is considered the possible development (formation) or compensation of the psychological qualities which is important for the successful performance of the activity and recommendations are given on the non-conflict personality reorientation in case of an insurmountable contradiction between the positive motivation to the activity and the discrepancy of the qualities of the individual with its requirements $[1,2$, $4,8,9]$.

Consequently, the psychological analysis of professional activity consists of psychogram of a profession and psychogram, carried out according to a certain algorithm, a scheme in which its purpose, task, procedure of conduction and formulation of results are defined. Examples of professional psychograms (schemes) are presented in a number of works by such scholars as: V. Bodrov; A. Dmitrieva, A. Krylov, A. Naftuliev [1, 9].

The purpose of the paper is to determine the rating of expert assessments of professionally important qualities of managers of international organizations according to the indicators of "Professiographical questionnaire by O. Lipmann" as a determinant of the success of their professional activities.

Materials and methods. The basis of the professional analysis of the activities of managers of international trade organizations (MTO) is the results of an empirical study a factor and correlation analysis based on 12 research methods and their 92 indicators that determine the professionally important qualities of the surveyed and the comparison of the identified factors with the indicators of "Professiographical Questionnaire by O. Lipmann. "

As a basis for a definition of the most important professional qualities for the managers of the MTO's the methodology "Professiographical questionnaire by O. Lipmann" has been chosen [6], which contains a list of 85 business-oriented characteristics and skills. It was decided to consult experts' opinion in order to study more objectively the important professional qualities in the field of MTO. The group of experts included 80 specialists with a professional experience of 5 to 10 years.

In the result of the survey of the group of experts based on the evaluation of a given list of professional qualities that may be important for the effective performance of their 
activities by future MTO specialists, as well taking into account the main components of the professional activity of experts, we have developed a rating of professionally important qualities.

The research by O. Lipmann questionnaire was conducted with the purpose of identifying such personality characteristics as: attentional, mnemonic, motivational, typological, imaginative and emotional, intellectual, volitional, linguistic and communicative. In addition, on the recommendation of experts, we have introduced two scales: competitiveness and ethnopsychological properties (instead of the scale of psychohomotorics and observation). The evaluation criteria for determining the importance of the suggested qualities were characterized by the following interpretative estimates:

1 - 2 points - if a quality is not very important for a given profession;

3 - 4 points - if a quality has some value;

5 - 6 points - if a quality is desirable, but is not obligatory;

7 - 8 points - if a quality is important for the successful activity of the MTO managers;

9 - 10 points - if a quality is mandatory and inherent for the managers of the MTO.

According to the results of the survey among experts based on the methodology "Professiographical Questionnaire" of O. Lipmann), the appropriate rank assessments of specific psychological qualities of the specialists have been formed.

Results and discussion. Here we present the results of expert assessments of professionally important qualities according to the indicators of the improved methodology of "Professiographical questionnaire of O. Lipmann". Thus, it was found that the highest estimates were obtained for characteristics such as linguistic and ethnopsychological (respectively $9.9 \pm 0.1 \mathrm{~b}$ and $9.7 \pm 0.3 \mathrm{~b}$.), competitiveness $(9.5 \pm 0.5 \mathrm{~b}$. $)$, imaginative $(9,4 \pm 0,6$ b. $)$, motivational $(9,3 \pm 0,7$ b. $)$, communicative $(9,2 \pm 0,8$ b. $)$, typological ( $8,8 \pm 1,2$ b.), volitional $(8,6 \pm 1,4$ b. $)$, emotional $(8,5 \pm 1,5$ b.), intellectual $(8,2 \pm 1,8$ b. $)$, attentive $(8,0 \pm 1), 9$ b. $)$ and mnemonic $(7,8 \pm 2,2$ b. $)$.

It is determined by ranking that in terms of the significance of the indicators of the methodology in the structure of professionally important qualities for managers those revealed in the first place are the language properties and in the second, ethnopsychological. This means that experts have given priority to the knowledge of one or more foreign languages, the ability to express their thoughts logical taking into account ethnopsychological peculiarities, sociocultural traditions, gestures, and language intonations of the inhabitants of the countries where the company's workplaces are located, that is, there are certain requirements for observing certain features that are inherent to a particular international commercial organization.

According to experts the next following professionally important qualities are: competitiveness and imaginative (respectively, the third and fourth points by rating), characterizing the surveyed as capable of finding new nonstandard solutions ("thinking outside the box") in conditions of competition and risk, who are able to make prognoses for the course of events in market conditions, taking into account their probability, the ability to choose the nec- essary information from the whole volume and make conclusions in case of its contradictory and the ability to make the correct decision in the absence of information.

It was established by expert assessments that the motivational features of the surveyed are put in the fifth place, which determines their positive professional motivation, focus on the result, success, ability to self-fulfillment in the activity and find adequate solutions.

Communicative personality characteristics are already partially represented in the field of ethnopsychological interaction, but this important component in the structure of professionally important qualities for managers of international companies is identified by experts as a separate characteristic of the candidates.

The following qualities identified by experts are related to typological characteristics (seventh place according to rating); volitional field (eighth by rating); emotional sphere (ninth by rating). They reproduce such qualities as: balance, stressresistance, rapid reactions to unexpected stimuli, which predetermines such volitional peculiarities - persistence, ability to accurately execute the order, ability to work effectively for a long time, ability to maintain high activity, tempo, ability to take for a responsibility in difficult situations, as well as manifestations of emotional stability in making responsible decisions, self-control, rapid adaptation to new conditions.

The evaluation of the intellectual sphere (tenth by rating) indicates the significant impact of this individual-psychological quality on the efficiency of professional activity, as far as they determine the ability to examine the problem from both sides, to cover the nature of the relationship, the problem being studied. At the same time, due to the attentive properties (eleventh by rating), they are able to switch, maintain stability, able to distribute and focus attention.

In addition, the experts assessed the need for mnemonic properties (twelfth point by rating) above the middle level, which predetermine the ability to notice changes in the environment, the ability to easily memorize and reproduce verbal and visual material, and retain a large amount of necessary information.

Thus, summing up the results obtained according to expert assessments according to the "Professiographical questionnaire of O. Lipmann", it was established that according to the ranking hierarchy, the most important psychological qualities in the structure of professionally important qualities for managers of international companies revealed the peculiarities of organizational requirements for the knowledge of foreign languages, ethnopsychological peculiarities of interaction with partners in the countries there representative offices of MTO are located.

The next important in rating was the professional sphere in terms of the severity of the person's competitiveness and imaginative properties, followed by motivational and communicative spheres, followed by typological and emotional-volitional features and the cognitive field of surveyed (intellectual, attentional, and mnemic properties).

Conclusions and perspectives of further research. It was established that the indicators of the "Professiographical questionnaire of O. Lipmann" correlate with the results of factor and correlation analyzes obtained by us. 
It is determined that according to the analysis of empirical data in the structure of professionally important qualities of managers of international trade organizations, six factors are determined that determine the effective functioning of the individual, namely: organizational factor F1 (according to the questionnaire of O. Lipmann, it is language and ethnopsychological properties); professional F2 - is a competitive and imaginative characteristics; F3 - motivational factor, similar to the questionnaire; F4 - communicative, corresponding to the rating of expert assessments of the fifth communicative psychological quality ; F5 functional-dynamic, which is conditioned by estimations of the typological and emotional-volitional sphere of the surveyed; F6 - intellectual, which corresponds to the expert assessments of the intellectual and cognitive spheres of the surveyed.

It was found out that the functional interaction of the determined six factors as structural determinants of professionally important qualities of managers of international companies suggests possible weakness of some functions and thus intensive strengthening of others, which in complex determines the effectiveness of professional activity of specialists.

The perspective of further research is that we can begin forming an analytical professional psychogram in accordance with the improved and adapted scheme as for the peculiarities of the professional activity of managers of international commercial companies.

\section{REFERENCES}

1. Bodrov, V.A. Psychology of professional fitness / V.A. Bodrov - M .: PERSE, 2001. - $511 \mathrm{p}$.

2. Karamushka, L.M. Motivation of entrepreneurial activity. / L.M. Karamushka, N.Y. Khudiakova - Kyiv-Lviv: "Spolom", 2011. - 206 p.

3. Klimov, E.A. Psychology of a professional. M.: Publishing house "Institute of practical psychology"; Voronezh: NPO "MODEK", 1996 - 400 p.

4. Korolchuk, M.S., Theory and Practice of Professional Selection / M.S. Korolchuk, V.M. Krainyuk - K .: Nika-Center, 2010. $536 \mathrm{p}$.

5. Makarenko, M.V. Fundamentals of professional selection of military specialists and methods of study of individual psychophysiological differences between people / Institute of physiology.by.O. O. Bogomolets National Academy of Sciences of Ukraine; Research sciences. center humanist. problems of the Armed Forces of Ukraine. - K .: 2006 - 395 p.
6. Nikiforov G.S. Workshop on Psychology of Management and Professional Activities // G.S. Nikiforov, M.A. Dmitrieva, V.M. Snetkov Tutorial. - SPb .: Rech, 2003. - 448 p.

7. Entrepreneurship: psychological, organizational and economic aspects: vs. Manual / S.D. Maksimenko, A.A. Mazaraki, L.P. Kulakovskaya, T.Y. Kulakovsky - K: Kyiv. National trade.econ. University., 2012. - 720 p.

8. Pryazhnikov N.S. Methods of activating professional and personal self-determination: study. method, way. / N.S. Pryazhnikov; RAO; Moscow psychol.-social. in-t - [2nd ed.]. - Moscow: Voronezh: NOO MODZK, 2003. - 392 p.

9. Psychology of Labor and Engineering Psychology: Textbook ed. A.A. Krylov - L.: Publishing house in Leningrad. Un-ta, 1999. - $224 \mathrm{p}$.

10. Psychological provision of professional activity: theory and practice / Ed. prof. G.S. Nikiforov - SPb .:Rech, 2010. - 816 p. 